\title{
Using TAM model to empirically examine students' attitudes towards e-services in college of business administration
}

\author{
Saeed Ali Omar Bahaj ${ }^{\text {a* }}$ Khaled Salmen Aljaaidi ${ }^{\mathrm{b}}$ and Tarig Mohamed Ahmed
}

${ }^{a}$ Management Information System Department, College of Business Administration, Prince Sattam bin Abdulaziz University, Saudi Arabia ${ }^{b}$ Accounting Department, College of Business Administration, Prince Sattam bin Abdulaziz University, Saudi Arabia

\begin{tabular}{l}
\hline C H R O N I C L E \\
\hline Article history: \\
Received: December 18, 2018 \\
Received in revised format: Feb- \\
ruary 12, 2019 \\
Accepted: February 14, 2019 \\
Available online: \\
February 14, 2019 \\
\hline Keywords: \\
TAM \\
e-service \\
Ease of use \\
Saudi Arabia \\
\hline
\end{tabular}
A B S T R A C T

\begin{abstract}
This study examines the relationships between Perceived Ease of Use and Perceived Usefulness with actual use of E-Services among 189 students from College of Business Administration (CBA) at Prince Sattam bin Abdulaziz University (PSAU) for the academic year 2017/2018. Using a survey-based methodology based on TAM perceptive, the results show that Perceived Ease for Use (PEU) and Perceived Usefulness (PU) had positive associations with Actual Use (AU) of E-Services among CBA students. Thus, the result of this study supports the prediction of TAM theory. The results of this study should be useful to educational policy makers in Kingdom of Saudi Arabia (KSA) and elsewhere, as there is an opportunity of enhancing the E-Services in the academic con-
\end{abstract} text.

(C) 2019 by the authors; licensee Growing Science, Canada

\section{Introduction}

Information technology (IT), according to Roca et al. (2006), is capable of transforming the means through which we access and learn information in two crucial means. First, IT allows us to efficiently and swiftly accomplish a number of activities we normally do. It is also very flexible and has better access. Secondly, IT allows us to accomplish issues that we are not able to do or in a substantially different ways. Through IT, a completely new environment is experienced in the course of learning which takes place outside the curricula and classrooms. Like other systems of information, the achievement of e-learning is pegged majorly on user contentment among other issues which will ultimately upsurge the intention user to still utilize it. Khee et al. (2014) noted that the new trending technology being applied in education worldwide today has influenced all learning and teaching aspects in higher learning institutions. As cited by Ramayah (2006), the technology advent has reformed how commercial activities are accomplished at the present. The sector of education is not sidelined since Internet advent has changed how teaching is conducted and how learners acquire information. Various scholars including Mirza and Mahmood (2012); Abbasi (2011); Dadzie (2005); Sutarso \& Suharmadi (2011); Nedeva \& Zlatev (2013); Khwaldeh et al. (2017) and Kim-Soon et al. (2014) argue that the higher education institutions are experiencing an extraordinary rate of growth. This tendency majorly influences on new empowering know-

* Corresponding author.

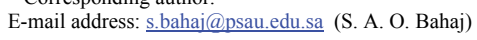

(C) 2019 by the authors; licensee Growing Science, Canada doi: $10.5267 /$ j.msl.2019.2.006 
how, which has simplified the online delivery of academic packages. Educational technology is at present among the most crucial discussion and debate issues amongst scholars and academicians. Higher education sector has been leading in online service delivery. Adoption of technology appears very crucial in availing latest information to learners who exploit it in a better and also very creatively. Information resources are among the electronic tools and services, which are availed at the universities. Electronic services are swiftly becoming a requirement in educational institutions. The primary objective of electronic services of students is to provide all educational related information and data to learners during their educational lives and even after graduating. Thus, it integrates and gathers all educational information from various university systems and is used as a meeting point amongst systems like library service, finance system, grading and academic system and e-learning system (the LMS/LCMS).

According to Davis (1989) and Davis et al. (1989), TAM (Technology Acceptance Model) (Al-rahmi \& Othman, 2013; Moon \& Kim, 2001) has been spread among the speculative models, which try to justify how technology users will consent and utilize it. Davis et al. (1992) extended this model developing nations like Arabic states (e.g., Saudi Arabia), which unlike the industrialized nations, have not utilized it. The model claims several contributing factors will determine how a user will adopt the new technology. Perceived usefulness (PU) and Perceived Ease of Use (PEU) are postulated to be the essential factors of acceptance by the users. In the electronic services context, these two determinants are crucial in determining how the learners perceive the electronic services of the PSAU. This has marked stern study gap as learners react to electronic services acceptance vary from one culture to another. Consequently it has become obligatory to access the issues affecting the usage of the electronic services available in institutions of higher educational in various cultures. Thus at Prince Sattam bin Abdulaziz University, the scarcity of electronic services in higher educational sector originates the stimulus for researching these factors. Specifically, the students at the college of Business Administration have been appointed purposely of this study. Particularly, little is understood and a lot of questions are unanswered concerning factors affecting Saudi Arabia's electronic services. To the best of the researchers, there are no statistical proves which permit conclusion to be reached concerning the usage of the electronic services by the students at Prince Sattam bin Abdulaziz University, Business Administration College. This article is an extension attempted to the present study at the Saudi Arabian context. It is conducted in a diverse educational scenario.

The main objective of this study is to examine the factors influencing the use of the available E-Services. Specifically, this research explores the extent to which learners utilize the electronic services of PSAU basing on the way they perceive the usefulness and the ease of electronic services related usage. The current research aims at understanding the issues of Perceived Ease of Use (PEU) and Perceived Usefulness (PU) based on Electronic services. Hence, comprehending the issues affecting the exploitation the electronic services will avail more leverage to promote acceptance by user as well as increasing the use of Electronic services amongst learners in years to come. Ideally, this research is crucial due of its role, which raises number of studies on Perceived Ease of Use and Perceived Usefulness concerning Electronic services in institutions of higher education. In addition, it provides a more value to this research since it is a study accomplished at KSA situation. An organized study will result to accurate and good data concerning Perceived Ease of Use and Perceived Usefulness of Electronic services amongst the university learners. Therefore, this research will assist in giving perception on the speculation, higher education as well as the student body and also will create an understanding on the way to motivate the learners to embrace Electronic services. The outcome from this research could be utilized by officers concerned with Electronic services to either expand the system or use the information to look for means enticing students to use Electronic services. Moreover, for knowledge body, this research will advance the precise explanation concerning the adoption of technology. This research also utilizes the TAM in the situation of electronic acceptance of the electronic services by PSAU learners. It also suggests Perceived Ease of Use and Perceived Usefulness being the construct to promote the accepting of a behavioral usage of Electronic services in the context of Education sector. 
The remainder of the paper proceeds as follows. The next section briefly discusses the literature review and the hypotheses development. The third section describes the research design and methodology. The empirical results and discussions of the study are reported in the fourth section while in the final section, conclusions and implications are drawn.

\section{Literature review and hypothesis development}

\subsection{E-service at Prince Sattam bin Abdulaziz University}

In view of the growth in a society driven by technological advancement and electronic services that is an impact of the necessity to undertake the transactions efficiently and faster, IT Deanship and PSAU Distance Learning have developed a united portal of electronic services. To reach every the e-service with ease, the portal provides access to every electronic service at a specific point. The portal of services which Dr. Abdul Rahman Al Asimi, Chancellor at PSAU initiated, is perceived as IT integrated portal which helps the countrymen, learners, workforce and stakeholders of the faculty. It gives over 94 electronic services, aiming at lowering time and energies needed to complete the communications. Students, employees, and members of the faculty are able to utilize the electronic services through the use of one time sign-on system, whereas the countrymen are capable of using it right. In addition, the platform entails a part devoted to the electronic services news portal. The following are the electronic services available to students at PSAU:

(1) Academic Services platform: It comprises of many types of educational services, which assist the learner, and members of the faculty. It allows the learner during registration, sending of letter requesting loans or release and dropping or adding courses. It also allows the learner to request for a transfer from one college to another. Moreover, through this platform, members of faculty are capable of tracking their classes, courses, and the learners as well as availing consultation services to the students. (2) E-Mail: Every learner receives the service immediately after acquiring a one time-sign-on username. It provides them an e-mail account linked to the university's domain. (3) E-learning platform: Blackboard allows the learner and member of the faculty to undertake the courses registered electronically in the system. It provides the members of the faculty member with various academic and important tools including setting of homework, exams as well as correcting them. He is also possible for the users to upload and consolidate the content of the courses, and also track the status of the learners. Blackboard is linked to a systems package like exams system, virtual classroom system and also SMS system. (4) Summer Training System: Summer training is among of the crucial activities in the learner's education period. It provides the instructor and the learner with an e-environment interactive system. The systems procedures begin from advertising the training vacancy, then, tracking the learner and lastly evaluating him. Also, it provides the training time in accordance with the learners major. (5) Calculation of GPA: It allows the learners to determine their semester and GPA grades. (6) Students' Employment System: It is a system, which shows the presented vacancies. It allows the potential applicant to fill the job application and interactively check the procedure on the field application. (7) Community Service Training Center: It allows the beneficiaries to check and register electronically in the courses trained and diplomas available Community Service Deanship as well as Continuous Education. It also allows the attraction of new trainers in center. (8) Electronic-Amend Registration options: Through the platform, the students admitted will have the option to change their selected courses during registration. (9) Students' Activity Services: It is designed in conjunction with the Students Affairs Dean. Its objective is to allow the campuses to electronically arrange the students' activities beginning with the publications and electronic invitations and ending with the registrations of students as well as follow up. (10) Tawasol System: It avail a simple but efficient means of filing a request as a suggestion, complaint or to inquire anything from official within the university. It allows those requesting to track the status of their application through sending SMS or e-mails. Conversely, it allows the process the application by the academic officers. It gives the top administrators the capability of controlling all the actions accomplished using the application, and also, checking related reports and signs. (11) Release Letter: It allows the learner to apply for a letter clearance 
from the institution depending on situations like dropping out, during graduation of moving from one university to the other. (12) Graduation Certificate Service: It allows the learner to acquire an original copy of certificate of graduation. (13) Student Status Service: It allows the external bodies to scrutinize the learner's data. (14) Graduation Projects: A system allows senior learners to apply for proposed topics for graduation project by departments at PSAU, and tails the complete steps of the project of graduation project during the course of various users like as the supervisors and the students. (15) Semester Re-Join Service: It allows the learner to continue with his academic training. (16) Transferring Service: It allows the learner to be move to PSAU from any university. (17) Postgraduate Study Academic Recommendation: Through this portal, the student will be able make a requisition concerning academic recommendation verifying his suitability for postgraduate studies. (18) Graduation Certificate Service: It allows the learner to acquire an original copy of certificate of graduation.

\subsection{Technology Acceptance Model (TAM)}

The TAM (Technology Acceptance Model), a theory originally advanced by Davis (1989) is the primary theory, which marks the foundation of the study and is a speculative extension linked to Theory of Reasoned Action (TRA). According to Davis (1989) and Davis et al. (1989), TAM theory is believed the most extensively established model compared to other theoretic models, which try to justify the relationship between satisfaction and attitude of user and behavioral goal. Fishbein and Ajzen (19751) and Ajzen and Fishbein (1980) argued that the TAM is established on the TRA which forecasts user acceptance referring to the impact of two issues: Perceived Usefulness and Perceived Ease of Use. TAM postulates that user opinions on usefulness and ease of use define attitudes in the utilization of the system. Davis (1986) views that both PU and PEU are opinions influencing on purpose of using technology, though PEU has also a direct impact on PU. Additionally, Davis et al. (1989) postulate that a later progress of TAM is the BI to be utilized as a fresh variable, which would be influenced, directly by PU and goal to utilize social media (Kwon \& Wen, 2010; Mazman \& Koçak-Usluel, 2010; Pelling \& White, 2009; Woje et al., 2013; Yang et al., 2011).

PU speaks of the belief by potential user that embracing a particular technology will lead to an improved performance. According to Davis (1986) and Davis (1989), PEU means the extent at which a person expects no mental and physical challenges in embracing the technology at stake. In particular, PEU demonstrates the magnitude of effort that a person requires to while applying an advent in technology. Therefore, PEU and PU are the two appropriate notions for defining aims of applying technology. Earlier scholars have attempted to justify that TAM demonstrate behavior of adoption of various systems and technologies of information (Ma \& Liu, 2004; Yousafzai et al., 2007). Kalin (2012), argued that before one can knows the importance of technology, he/she must understand better on how our learners use it through TAM.

\subsection{Perceived Ease of Use}

Perceived Ease of Use has been defined in a number of ways. In 1989, Davis argued that a requisition that seems easy to adopt is more possible to be embraced by users relative to others. Many researches have been executed to find out the impact of perceived usefulness on technology acceptance. Rogers (1995) claimed that the acceptance of a technology relies on the degree to which every innovation is understood and seen as fairly simple to utilize and understand. The technology, which is seen as simple, appeals more users in relatively to the one that is complicated. The system of delivery has to be direct during its use so that less effort is applied. Moreover, Perceived Ease of Use is also defined as "the extent to which an individual considers that applying a given system requires minimum effort", (Dholakia \& Dholakia, 2004). Additionally, Teo (2001) argued that it referred to "the extent at which the operator presumes the system use to be easy to him or her". Furthermore, the ISO 9241 reach a conclusion that "Perceived Ease of Use refers to the degree at which a technology could be adopted by particular users so as to efficiently and effectively attain particular goals, while satisfying in a particular use context (ISO, 
1998)". Rao Hill and Troshani (2007) believed that, the outcome of Perceived Ease of Use on the aim of the while accepting a discovery either indirectly or directly has been researched well and recorded in the literature. According to Zhang et al. (2008), the TAM presumed that learners are expected to accept a new innovation to the degree which they consider helpful in enhancing their performance in research and the extent of every person expectation in embracing a new innovation would not require any intellectual power ease of use. Davis (1989) believes that perceived usefulness possess more straightforward impact on physical more than attitude, while Perceived Ease of Use impact on the behavior and attitudes. Earlier studies by Dishaw and Strong (1999) show that the theories which TAM included can be useful to a various computer innovation; but an extended model or combined model can make it potential in providing more power of explanation relative to using only the original model.

Among the resources and tools of Electronic service offered by the university is the information resources. E-services are quickly gaining fame in the academic sector. The major target of e-services of the student is to offer any related academic information and data to learners while they are going on with their studies even after completion. Thus, Mirza and Mahmood (2012), Abbasi (2011), Dadzie (2005) Sutarso and Suharmadi (2011), Nedeva and Zlatev (2013), Khwaldeh et al. (2017) and Kim-Soon et al. (2014) believe that it combines and integrates all content of education from various systems within the university and is used as a meeting point connecting systems like finance, library service, the LMS/LCMS or the e-learning system, grading and academic system. Purposely for this research, the Perceived Ease of Use means "the extent to which learners considers that the use of E-Services will not involve the mental and the physical and input that, as a result, will improve the actual usage of ElectronicServices". Therefore, the following hypothesis is proposed:

$\mathrm{H}_{1}$ : There is a positive relationship between Perceived Ease of Use of the E-Services and the use of the E-Services.

\subsection{Perceived Usefulness}

TAM believes that learners are expected to embrace a new innovation to the degree, which they consider helpful to them by enhancing their academic progress (usefulness). Dholakia and Dholakia (2004) referred Perceived Usefulness to be "the extent at which an individual consider that applying a given system will improve his/her performance in the job sector". Additionally, Perceived Usefulness is also referred to as "the extent at which a person considers that utilizing the services would result to attaining a given objective" (Dickinger et al., 2006). In accordance with Lexhagen et al. (2005), acceptance of information system research provided that "a system which does not assist a worker in their task is unlikely to be accepted warmly despite how best implementation efforts will be". Furthermore, note that Perceived Usefulness is among the powerful variable of clarifying the attitude variance (Daneshgar et al., 2007). Particularly for this research, the Perceived Usefulness means "the extent at which a learner considers that utilizing E-Services will improve his/her education and performance in academics". At the resources and tools of Electronic service offered in the institution, information resources should be included. Eservices are rapidly gaining popularity the educational institutions. The leading aim of learners' electronic services is to offer all information and data associated with education to learners in the course of their academic odysseys and even beyond. Hence, according to Mirza and Mahmood (2012), Abbasi (2011), Dadzie (2005), Sutarso and Suharmadi (2011), Nedeva and Zlatev (2013), Khwaldeh et al. (2017) and Kim-Soon et al. (2014), it combines and links every content considered educational from various systems within the institution and used as a hub linking systems like academic and grading system, financial system, library service and the LMS/LCMS or e-learning system. Perceived Usefulness has been noted by earlier scholars like Alenezi et al. (2015), Alalwan et al. (2016), Abdullah et al. (2016) and Obeidat et al. (2016) to directly influence the E-Services Actual Use. Therefore, the following hypothesis is proposed:

$\mathrm{H}_{1}$; There is a positive relationship between Perceived Usefulness of the E-Services and the actual use of the E-Services. 
The E-Services actual use might be justified by the forecast of the Davis' (1989) model, TAM, which was model initially launched by him. According to Fishbein and Ajzen (1975), Davis (1989) and Davis et al. (1989), TAM is an extension of TRA extension which forecasts user acceptance based on the impact of two determinants: Perceived ease of use and Perceived Usefulness. Regarding this study, Lederer et al. (2000) believed that the E-Services actual use in TAM is considered a frequency and time self-reported strategy in applying the application.

\section{Research design and methodology}

Based on the ATM theory developed Davis (1989) and derived from the prior literature (Rogers, 1995; Dholakia and Kholakia, 2004; Teo, 2001; Rao Hill \& Troshani, 2007; Zhang et al., 2008; Lou et al., 2000; Dishaw \& Strong, 1999; Mirza \& Mahmood, 2012; Abbasi et al., 2011; Dadzie, 2005; Sutarso \& Suharmadi, 2011; Nedeva \& Zlatev, 2013; Khwaldeh et al., 2017; Kim-Soon et al., 2014; Dickinger et al., 2006; Lexhagen et al., 2005; Daneshgar et al., 2007; Shin \& Kim, 2008), the present study uses a survey-based methodology to obtain data from the respondents. This study adopts and modifies a selfadministrative survey questionnaire that has been developed to be applicable for the academic context. The questionnaire was divided into two sections, namely; section A and section B. In specific, section A comprised 9 statements designed to ascertain the views of the College of Business Administration students on factors influencing their use of the university E-Services. A five-point Likert scale was used in this section and the respondents were required to state the extent to which they agreed or disagreed with the statements in the questionnaire. Section A comprised questions eliciting demographic characteristics. The sample of the study comprised 189 College of Business Administration students enrolling for the academic year 2017/2018 at Prince Sattam bin Abdulaziz University in Saudi Arabia. A total of 250 questionnaires were distributed to College of Business Administration students during classroom time using a simple random sampling. Students were asked to return back the questionnaires after two weeks. The response rate for this study was 75.6\%. Variables included in the model of this study are "Perceived ease to use" (PEU) and "Perceived Usefulness"(PU) to identify reasons contributing to the actual use of E-Services among students. Actual use is used as the dependent variable in the model. To measure the impact of the individual factors, a 3-item measure was used to examine the Perceived Ease of Use and a 3-item measure was used to test the Perceived Usefulness. The dependent variable "Actual Use" is measured using a 3-item measure to determine the extent to which E-Services are used among students. The functional equation of regression model is utilized to determine the extent of the association of each of the independent variable on actual use as shown in Eq. (1):

$$
\mathrm{AU}=\beta 0+\beta 1 \mathrm{PEU}+\beta 2 \mathrm{PU}+\mathrm{e}
$$

\section{Empirical results and discussion}

\subsection{Descriptive statistics and correlation analysis}

Demographic characteristics of students in this study are gender, age, level of study and CGDP as shown in Table 1. Based on the demographic information depicted in Table 1, the majority of students (76.7\%) were male. Regarding the age, the majority of the students $(48.7 \%)$ are between 21 and 23 year old. In terms of CGPA, the majority of students (25.4\%) obtained between 3.0 -3.49 cumulative grade point averages. The Pearson correlations among the Actual Use (AU), Perceived Ease of Use (PEU) and Perceived Usefulness (PU) are presented in Table 2. Table 2 illustrates the Pearson correlation coefficient at $95 \%$ confidence level. 
Table 1

Profile of respondents

\begin{tabular}{lll}
\hline Demographic characteristics & Frequency $(\mathbf{n}=\mathbf{1 8 9})$ & Percent \% \\
\hline Gender: & & \\
Male & 145 & 76.7 \\
Female & 44 & 23.3 \\
\hline Age: & & \\
$18-20$ & 75 & 39.7 \\
$21-23$ & 92 & 48.7 \\
$24-26$ & 18 & 9.5 \\
26 and above & 4 & 2.1 \\
\hline Level of study: & & \\
Preparatory Year & 18 & 9.8 \\
Freshmen & 48 & 25.4 \\
Sophomore & 41 & 21.7 \\
Junior & 35 & 18.5 \\
Senior & 47 & 24.6 \\
\hline CGPA & & \\
Less than 3.0 & 45 & 23.8 \\
$3.0-3.49$ & 48 & 25.4 \\
$3.5-3.99$ & 26 & 13.8 \\
$3.4-4.9$ & 24 & 12.7 \\
$4.5-5$ & 46 & 24.3 \\
\hline
\end{tabular}

Table 2

Pearson Correlation Analysis results $(\mathrm{n}=189)$

\begin{tabular}{lccc}
\hline & AU & PEU & PU \\
\hline AU & 1.00 & & \\
PEU & $0.504^{* *}$ & 1.00 & \\
PU & $0.539^{* *}$ & $0.697^{* *}$ & 1.00 \\
\hline
\end{tabular}

** Significant at 1 per cent level (2-tailed).

*Significant at 5 per cent level (2-tailed).

The correlation matrix confirms that Perceived Usefulness (PU) and Actual Use (AU) with a correlation coefficient of 0.539 and then between the Actual Use (AU) and Perceived Ease of Use (PEU) with a correlation coefficient of 0.504. Thus, the Pearson Correlation Analysis supports the TAM theory's prediction and the supportive empirical research. Importantly, due to the limitation of the Pearson Correlation Analysis, further regression analysis is required for more support.

\subsection{Regression results and discussions}

\subsubsection{Reliability test}

The dependent and independent variables examined in this study were tested for their reliability as shown in Table 3. The reliability indicates to the accuracy which concern on stability, dependability and consistency of an instrument. In this study, the Cronbach's alpha coefficient is used, which is based on the average correlation of items within a test if the items are standardized. Hari et al. (1998) documented that the lower limit of acceptability could be .60 .

Table 3

Mean scores and analysis of internal consistency

\begin{tabular}{lcccc}
\multicolumn{1}{c}{ Variables } & No. of Items & Mean & SD & Cronbach's Alpha \\
\hline Perceived ease of use & 3 & 3.705 & .890 & .642 \\
Perceived Usefulness & 3 & 3.429 & 1.494 & .666 \\
Actual use & 3 & 4.042 & .882 & .760 \\
\hline
\end{tabular}

As displayed by Table 3, all the alpha coefficients exceed the recommended minimum cutoff level of .60 . Thus, the items measuring the variables are considered acceptable. In another word, the instruments are reasonably accepted for the purpose of reliability. 


\subsubsection{Regression results}

Table 4 shows that the coefficient of determination $\left(\mathrm{R}^{2}\right)$ for the model is equal to 32.1 per cent which means that all the variables accounted for $32.1 \%$ of the variance in E-Services actual use. The table also depicts that the model is a statistically significant where the $\mathrm{F}$ test statistic $=42.052$ with a $p$-value $<$ 0.000 .

\section{Table 4}

Summary of the model

\begin{tabular}{|c|c|c|c|c|c|c|}
\hline $\mathbf{R}$ & R square & $\begin{array}{l}\text { Adjusted R } \\
\text { square }\end{array}$ & $\mathbf{F}$ & \multicolumn{2}{|r|}{ Sig. } & \\
\hline .566 & .321 & 0.31 & 42.052 & \multicolumn{3}{|c|}{.000} \\
\hline Variables & & \multicolumn{2}{|c|}{ Expected sign } & Coeff. & $t$ & Sig \\
\hline (Constant) & & \multirow{2}{*}{\multicolumn{2}{|c|}{+}} & & 10.117 & .000 \\
\hline Perceived ease to use & & & & .241 & 2.797 & .006 \\
\hline Perceived Usefulness & & \multicolumn{2}{|c|}{+} & .372 & 4.318 & .000 \\
\hline
\end{tabular}

Table 4 shows the beta coefficients for the independent variables. The largest $t$ statistics is -4.318 ( $p$ value $<0.001)$ which is the Perceived Usefulness. This indicates that the PSAU's College of Business Administration's students perceive the university's E-Services as a useful technology. This determinant has a degree of importance in explaining the actual use of E-Services. This result is consistent with the prediction of TAM theory and supportive extant research. The second $t$ statistics is 2.797 ( $p$-value $<$ 0.001) which is the Perceived Ease of Use of E-Services. This shows that the College of Business Administration's students perceive the PSAU's E-Services as an easy technology to be used with exerting any physical or mental efforts. This result is in line with suggestion of TAM theory and the supportive literature. Thus, hypotheses $\mathrm{H}_{1}$ and $\mathrm{H}_{2}$ were supported.

\section{Conclusions and implications}

The main objective of this study was to examine the factors influencing the use of E-Services among College of Business Administration's students at PSAU. A sample of 189 College of Business Administration students at Prince Sattam bin Abdulaziz University in Saudi Arabia enrolling for the academic year 2017/2018 has been used for distributing out a survey questionnaire as a means of collecting data. Two factors (Perceived Ease of Use and Perceived Usefulness) were determined as contributing factors influencing the extent to which E-Services were used by students. Using the multiple regression, consistent with the ATM theory and the previous studies, this study has found that the Perceived Ease of Use and Perceived Usefulness were important factors influencing the level of using the E-Services among students of College of Business Administration. This implies that Saudi government, educational policy makers and universities should motivate educational environment by supporting the technological infrastructure at the university and enhancing the students' confidence in using E-Services. One technique is by encouraging students to involve in E-Services activities. Further, colleges should conduct conferences, seminars and workshops that enhance the students' ability in using IT applications. Moreover an attempt should be made to update and keep pace with the current developments and issues in academic research and database. One limitation of this study could be attributed to the self-reporting bias. Filling in the survey questionnaire, students may misreport their opinions to make the surveys look better. Another limitation of this study is the number of factors introduced in the model. The results of this study will be of interest to the educational policy makers, researchers and academic community due to a lack of formal research body addressing the issues of E-Services in Kingdom of Saudi Arabia and, therefore, this study will provide with substantial information about issues in the educational context of Saudi Arabia to count on, in the future, as premise data. Regarding future line of research, efforts should be put at introducing other determinants influencing students' usage of E-Services such as performance expectancy, effort expectancy, social influence and facilitating conditions. Future line of research may investigate the usage of E-Services among academic and administrative staff. Further research should replicate this model to 
determine its validity in different contexts of Saudi universities and GCC countries, in different time periods, and with different sample size. These limitations may motivate more future research in the GCC setting.

\section{Acknowledgement}

The authors would like to thank Prince Sattam bin Abdulaziz University for sponsoring and supporting preparing and publishing this paper throughout the "Specialized Research Grant Program" under the Research Number 2017/02/7976. We would like also to express our utmost appreciation to the Dean of Deanship of Scientific Research and the staff in there for their kindness and assistance during the process of conducting this research.

\section{References}

Abbasi, M. N., Malik, A., Chaudhry, I. S., \& Imdadullah, M. (2011). A study on student satisfaction in Pakistani universities: the case of Bahauddin Zakariya University, Pakistan. Asian Social Science, 7(7), 209.

Abdullah, F., Ward, R., \& Ahmed, E. (2016). Investigating the influence of the most commonly used external variables of TAM on students' Perceived Ease of Use (PEOU) and Perceived Usefulness (PU) of e-portfolios. Computers in Human Behavior, 63, 75-90.

Alalwan, A. A., Dwivedi, Y. K., \& Williams, M. D. (2016). Customers' intention and adoption of telebanking in Jordan. Information Systems Management, 33(2), 154-178.

Alenezi, H., Tarhini, A., \& Sharma, S. K. (2015). Development of quantitative model to investigate the strategic relationship between information quality and e-government benefits. Transforming Government: People, Process and Policy, 9(3), 324-351.

Al-rahmi, W., \& Othman, M. (2013). Using TAM model to measure the use of social media for collaborative learning. International Journal of Engineering Trends and Technology (IJETT), 5(2), 90-95.

Dadzie, P. S. (2005). Electronic resources: access and usage at Ashesi University College. Campus-Wide Information Systems, 22(5), 290-297.

Daneshgar, F., Aurum, A., \& Potukuchi, S. (2007). Adoption of instant messaging technologies by university students. ACIS 2007 Proceedings, 70.

Davis, F. D. (1985). A technology acceptance model for empirically testing new end-user information systems: Theory and results (Doctoral dissertation, Massachusetts Institute of Technology).

Davis, F. D. (1989). Perceived usefulness, perceived ease of use, and user acceptance of information technology. MIS quarterly, 17(3), 319-340.

Davis, F. D., Bagozzi, R. P., \& Warshaw, P. R. (1989). User acceptance of computer technology: a comparison of two theoretical models. Management science, 35(8), 982-1003.

Dholakia, R. R., \& Dholakia, N. (2004). Mobility and markets: emerging outlines of m-commerce. Journal of Business research, 57(12), 1391-1396.

Dickinger, A., Arami, M., \& Meyer, D. (2006, January). Reconsidering the adoption process: enjoyment and social norms - antecedents of hedonic mobile technology use. In System Sciences, 2006. HICSS'06. Proceedings of the 39th Annual Hawaii International Conference on (Vol. 1, pp. 23a-23a). IEEE.

Dishaw, M. T., \& Strong, D. M. (1999). Extending the technology acceptance model with task-technology fit constructs. Information \& Management, 36(1), 9-21.

Fishbein, M., \& Ajzen, I. (1975). Belief, attitude, intention and behaviour: An introduction to theory and research. Reading. MA: Addison-Wesley

Kalin, J. (2012). Doing what comes naturally? Student perceptions and use of collaborative technologies. International Journal for the Scholarship of Teaching and Learning, 6(1), 10.

Khee, C. M., Wei, G. W., \& Jamaluddin, S. A. (2014). Students' perception towards lecture capture based on the Technology Acceptance Model. Procedia-Social and Behavioral Sciences, 123, 461-469.

Khwaldeh, S. M., Al-Hadid, I., \& Masa'deh, R. E. (2017). The association between e-services web portals information quality and ICT competence in the Jordanian universities. Asian Social Science, 13(3), 156.

Kim-Soon, N., Rahman, A., \& Ahmed, M. (2014). E-service quality in higher education and frequency of use of the service. International Education Studies, 7(3), 1. 
Kwon, O., \& Wen, Y. (2010). An empirical study of the factors affecting social network service use. Computers in Human Behavior, 26(2), 254-263.

Lexhagen, M., Nysveen, H., \& HEM, L. E. (2005). Festival coordination: An exploratory study on intention to use mobile devices for coordination of a festival. Event Management, 9(3), 133-146.

Lou, H., Luo, W., \& Strong, D. (2000). Perceived critical mass effect on groupware acceptance. European journal of information systems, 9(2), 91-103.

Ma, Q., \& Liu, L. (2004). The technology acceptance model: A meta-analysis of empirical findings. Journal of Organizational and End User Computing (JOEUC), 16(1), 59-72.

Mazman, S. G., \& Koçak-Usluel, Y. (2010). Modeling educational usage of Facebook. Computers \&Education, 55 (2), 444-453.

Mirza, M. S., \& Mahmood, K. (2012). Electronic resources and services in Pakistani university libraries: A survey of users' satisfaction. The International Information \& Library Review, 44(3), 123-131.

Moon, J. W., \& Kim, Y. G. (2001). Extending the TAM for a World-Wide-Web context. Information \& management, 38(4), 217-230.

Nedeva, V., \& Zlatev, Z. (2013). Quality of the services provided by a university web portal. Applied Researches in Technics, Technologies and Education, 1(3), 173-180.

Obeidat, B. Y., Al-Suradi, M. M., Masa'deh, R. E., \& Tarhini, A. (2016). The impact of knowledge management on innovation: An empirical study on Jordanian consultancy firms. Management Research Review, 39(10), 1214-1238.

Pelling, E. L., \& White, K. M. (2009). The theory of planned behavior applied to young people's use of social networking web sites. CyberPsychology \& Behavior, 12(6), 755-759.

Ramayah, T. (2006). Interface characteristics, perceived ease of use and intention to use an online library in Malaysia. Information Development, 22(2), 123-133.

Rao Hill, S., \& Troshani, I. (2007). A conceptual framework and propositions for the acceptance of mobile services.

Roca, J. C., Chiu, C. M., \& Martínez, F. J. (2006). Understanding e-learning continuance intention: An extension of the Technology Acceptance Model. International Journal of human-computer studies, 64(8), 683-696.

Rogers, E. (1995). Diffusion of innovations (4th ed.). New York: The Free Press.

Shin, D. H., \& Kim, W. Y. (2008). Applying the technology acceptance model and flow theory to cyworld user behavior: implication of the web2. 0 user acceptance. CyberPsychology \& Behavior, 11(3), 378-382.

Sutarso, Y., \& Suharmadi, A. (2011). Promotion of E-Technology-Based Services a Case Study of E-Service Quality at a University in Indonesia.

Teo, T. S. (2001). Demographic and motivation variables associated with Internet usage activities. Internet Research, 11(2), 125-137.

Venkatesh, V., \& Bala, H. (2008). Technology acceptance model 3 and a research agenda on interventions. Decision sciences, 39(2), 273-315.

Venkatesh, V., Morris, M. G., Davis, G. B., \& Davis, F. D. (2003). User acceptance of information technology: Toward a unified view. MIS quarterly, 27(3), 425-478.

Woje, W., Tyrrell, T., \& Erdem, M. (2013). Exploring the behavioral aspects of adopting technology: Meeting planners' use of social network media and the impact of perceived critical mass. Journal of Hospitality and Tourism Technology, 4(1), 6-22.

Yang, Y., Wang, Q., Woo, H. L., \& Quek, C. L. (2011). Using Facebook for teaching and learning: a review of the literature. International Journal of Continuing Engineering Education and Life Long Learning, 21(1), 72-86.

Yousafzai, S. Y., Foxall, G. R., \& Pallister, J. G. (2007). Technology acceptance: a meta-analysis of the TAM: Part 1. Journal of Modelling in Management, 2(3), 251-280.

Zhang, S., Zhao, J., \& Tan, W. (2008). Extending TAM for online learning systems: An intrinsic motivation perspective. Tsinghua Science and Technology, 13(3), 312-317.

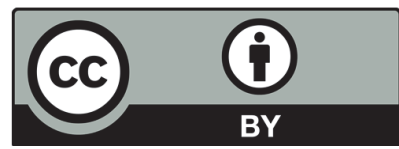

(C) 2019 by the authors; licensee Growing Science, Canada. This is an open access article distributed under the terms and conditions of the Creative Commons Attribution (CCBY) license (http://creativecommons.org/licenses/by/4.0/). 